\title{
Racial disparities in health care access among pediatric patients with craniosynostosis
}

\author{
*Zackary D. Brown, ${ }^{1}$ Amita K. Bey, MPH, ${ }^{1}$ Christopher M. Bonfield, MD, ${ }^{2}$ Ashly C. Westrick, MPH, \\ Katherine Kelly, ${ }^{1}$ Kevin Kelly, MD, DDS, ${ }^{3}$ and John C. Wellons III, MD, MSPH ${ }^{1,2}$ \\ ${ }^{1}$ Surgical Outcomes Center for Kids, ${ }^{2}$ Department of Neurologic Surgery, and ${ }^{3}$ Department of Plastic Surgery, Section of Surgical
} Sciences, Vanderbilt University Medical Center, Nashville, Tennessee

\begin{abstract}
OBJECTIVE Disparities in surgical access and timing to care result from a combination of complex patient, social, and institutional factors. Due to the perception of delayed presentation for overall health care services and treatment in African American patients on the part of the senior author, this study was designed to identify and quantify these differences in access and care between African American and Caucasian children with craniosynostosis. In addition, hypotheses regarding reasons for this difference are discussed.
\end{abstract}

METHODS A retrospective study was conducted of 132 children between the ages of 0 and 17 years old who previously underwent operations for craniosynostosis at a tertiary pediatric care facility between 2010 and 2013. Patient and family characteristics, age at surgical consultation and time to surgery, and distance to primary care providers and the tertiary center were recorded and analyzed.

RESULTS Of the 132 patients in this cohort, $88 \%$ were Caucasian and $12 \%$ were African American. The median patient age was 5 months (interquartile range [IQR] 2-8 months). African Americans had a significantly greater age at consult compared with Caucasians (median 341 days [IQR 192-584 days] vs median 137 days [IQR 62-235 days], respectively; $p=0.0012$ ). However, after being evaluated in consultation, there was no significant difference in time to surgery between African American and Caucasian patients (median 56 days [IQR 36-98 days] vs median 64 days [IQR 43-87 days], respectively). Using regression analysis, race and type of synostoses were found to be significantly associated with a longer wait time for surgical consultation $(p=0.01$ and $p=0.04$, respectively, using cutoff points of $\leq 180$ days vs $>180$ days). Distance traveled to primary care physicians and to the tertiary care facility did not significantly differ between groups. Other factors such as parental education, insurance type, household income, and referring physician type also showed no significant difference between racial groups.

CONCLUSIONS This study identified a correlation between race and age at consultation, but no association with time to surgery, distance, or family characteristics such as household income, parental education, insurance type, and referring physician type. This finding implies that delays in early health-seeking behaviors and subsequent referral to surgical specialists from primary care providers are the main reason for this delay among African American craniofacial patients. Future studies should focus on further detail in regards to these barriers, and educational efforts should be designed for the community and the health care personnel caring for them.

http://thejns.org/doi/abs/10.3171/2016.1.PEDS15593

KEY WORDS craniosynostosis; racial health care disparities; craniofacial

$\mathrm{C}$ RANIOSYNOSTOSIS is a congenital disorder marked by the premature fusion of 1 or more cranial sutures. ${ }^{5}$ Treatment is undertaken primarily to restore a more normal head shape for aesthetic reasons and secondarily to mitigate the risk posed by elevated intracranial pressure. Traditionally, the optimal time for surgical intervention is before 1 year of age as the bones are more malleable, bone regrowth is quicker and more likely to occur, and rapid brain growth benefits from skull remodeling. ${ }^{31}$ More recently, Patel et al. found that surgical correction within the first year of life (which was even more pronounced in the first 6 months of life) was associated with better long-

ABBREVIATIONS IQR = interquartile range; MCJCHV = Monroe Carell Jr. Children's Hospital at Vanderbilt; PCP = primary care physician; SES = socioeconomic status. SUBMITTED October 2, 2015. ACCEPTED January 20, 2016.

* Ms. Bey and Mr. Brown contributed equally to this work. 
term cognitive outcomes. ${ }^{22}$ Also, more minimally invasive options are available to use if the child is a few months old. ${ }^{14}$ For these reasons, it is advantageous for children to be seen in craniofacial clinics as early as possible for evaluation.

Racial and ethnic disparities in health status largely reflect differences in social, socioeconomic, and behavioral risk factors, as well as environmental living conditions. ${ }^{29}$ However, the relative contributions of access and timeliness of surgical care to these disparities is not clear. Previous studies suggest that minority races/ethnicities are less likely to have a regular source of care, arrange fewer physician visits, and have lower total health care expenditures. ${ }^{11}$ The purpose of our study was to identify and quantify differences in access and care between African American and Caucasian pediatric craniofacial patients with craniosynostosis. Specifically, we compared the time from birth to surgical consult and the time from consult to surgery, and also investigated numerous factors such as distance to primary care physician (PCP), distance to tertiary care center, age, family unit makeup, parental education, insurance type, household income, and referring physician type, to help explain any differences found.

\section{Methods \\ Study Population}

We retrospectively identified 140 patients (range 0-17 years old) who underwent surgical correction for craniosynostosis at the Monroe Carell Jr. Children's Hospital at Vanderbilt (MCJCHV) from 2010 to 2013. This study aimed to describe differences in care specifically between African American and Caucasian patients; therefore children of other races $(n=4)$ or without documented race information $(n=4)$ were excluded, leaving 132 patients for analysis. All demographic patient information was abstracted from electronic medical records and complemented with admission, discharge, and transfer information. Patient race, family unit structure, highest level of parental education, and number of other household children were recorded as documented in the medical record via patient report. Additionally, tests for normality indicated a nonnormal distribution, and therefore nonparametric statistics were used. Chi-square and Fisher's exact tests were used as appropriate and medians and interquartile ranges (IQRs) were reported. Backward stepwise logistic regression was conducted to control for confounding variables. Analyses were performed using SAS (version 9.4, SAS Institute). Statistical significance was set a priori at $\mathrm{p} \leq 0.05$.

\section{Outcome Variables}

To better understand how a factor affected a patient's ability to receive care, we focused on "availability" and "accessibility" of health care resources. Availability was defined as the presence of community providers (pediatricians, PCPs, or specialists) who could determine the patient's need for surgical consultation. Referring physician names were abstracted from the patient medical record and then categorized by physician type prior to analysis. We defined "accessibility" as whether the family had ad- equate resources (insurance, median household income, distance traveled for care) that allowed them to be able to use "available" resources. A previous study utilizing area-based socioeconomic status (SES) indicators (e.g., block group, census tract, and zip code levels) suggests that median income by zip code level can be used to track the impact of SES disparities on health outcomes in primary care networks. ${ }^{2}$ Similarly, median income captured from US Census reports based on geographic zip code (http://www.census.gov/quickfacts) was used as a proxy for households. The times from birth to the initial surgical consultation ("age at consult") and from the initial surgical consultation to the surgical intervention ("time to surgery") were recorded and analyzed. Also, the distances between the patient's home zip code to the zip code of their referring provider and between household zip code to MCJCHV were compared between groups. Distance was calculated using Google Maps (2014).

\section{Results \\ Demographics}

Overall demographic information is shown in Table 1. Of the 132 patients in our final cohort, approximately $88 \%$ were Caucasian, and more than half (64\%) were male. The median patient age was 5 months (IQR 2-8 months). Based on zip code of residence, the median income for most households (82\%) ranged from $\$ 25,001$ to $\$ 49,999$ (US Census reports). Fifty-eight percent of households had more than 1 child in the home. All patients $(n=132)$ had an established PCP, and $87 \%$ were referred for surgical consultation by a pediatrician. The most common craniosynostosis diagnoses in this surgical cohort were metopic synostosis (39\%) and sagittal synostosis (37\%).

Of all demographic variables assessed with univariate analyses, family unit structure-defined as whether the patient lived with 1 parent, both parents, or under foster parent/legal guardianship-was the only characteristic to significantly differ between races $(p=0.0019)$. Sex, parental education, insurance type, household income, diagnosis, and referring physician type were not significantly different between groups.

\section{Time to Referral and Surgery}

The median time from birth to initial surgical consultation for the overall cohort was 148 days (IQR 68-253 days; Table 2). African American patients were significantly older at initial consultation when compared with Caucasian patients (median 341 days [IQR 192-584 days] vs median 137 days [IQR 62-235 days], respectively; $p$ $=0.0012$, Table 2). However, we found no difference in age at consult among children presenting with different types of synostoses $(\mathrm{p}=0.09)$. When controlling for potential socioeconomic confounding variables (race, family unit structure, parental education, insurance, income, and type of synostoses), race and type of synostoses were significantly associated with an overall longer wait time for surgical consultation ( $p=0.01$ and $p=0.04$, respectively, using cutoff points of $\leq 180$ days vs $>180$ days). There was no significant difference in time to surgery once the child was evaluated by a specialist (median 64 days [Caucasian; 
TABLE 1. Demographic characteristics of African American and Caucasian pediatric patients with craniosynostosis

\begin{tabular}{|c|c|c|c|c|}
\hline Variable & Overall Cohort & African American & Caucasian & p Value \\
\hline No. of patients & 132 & 16 & 116 & \\
\hline Median age in mos (IQR) & $5(2-8)$ & $11(6-18.5)$ & $4(2-8)$ & \\
\hline Sex $(\%)$ & & & & 0.41 \\
\hline Male & $85(64)$ & $12(75)$ & $73(63)$ & \\
\hline Female & $47(36)$ & $4(25)$ & $43(37)$ & \\
\hline Family unit (\%) & & & & 0.0019 \\
\hline Single-parent household & $20(16)$ & $7(47)$ & $13(12)$ & \\
\hline Two-parent household & $104(82)$ & $7(47)$ & $97(87)$ & \\
\hline Foster care/legal guardians & $3(2)$ & $1(7)$ & $2(2)$ & \\
\hline Parental education (\%) & & & & 0.18 \\
\hline High school & $40(43)$ & $9(75)$ & $31(39)$ & \\
\hline GED & $4(4)$ & $0(0.0)$ & $4(5)$ & \\
\hline College & $42(46)$ & $3(25)$ & $39(49)$ & \\
\hline Post-graduate & $6(7)$ & $0(0.0)$ & $6(8)$ & \\
\hline Insurance (\%) & & & & 0.44 \\
\hline Private & $53(40)$ & $4(25)$ & $49(42)$ & \\
\hline Public & $71(54)$ & $12(75)$ & $59(51)$ & \\
\hline Military & $6(5)$ & $0(0.0)$ & $6(5)$ & \\
\hline Self-pay & $2(2)$ & $0(0.0)$ & $2(2)$ & \\
\hline Household income $(\%)^{*}$ & & & & 0.25 \\
\hline$\$ 0-\$ 25,000$ & $1(1)$ & $0(0.0)$ & $1(1)$ & \\
\hline$\$ 25,001-\$ 49,999$ & $108(82)$ & $11(69)$ & $97(84)$ & \\
\hline$\$ 50,000$ or more & $23(17)$ & $5(31)$ & $18(16)$ & \\
\hline Diagnosis (\%) & & & & 0.15 \\
\hline Metopic synostosis & $51(39)$ & $7(44)$ & $44(38)$ & \\
\hline Sagittal synostosis & $49(37)$ & $3(19)$ & $46(40)$ & \\
\hline Coronal synostosis & $16(12)$ & $2(12)$ & $14(12)$ & \\
\hline Lambdoidal synostosis & $2(2)$ & $1(6)$ & $1(1)$ & \\
\hline Multiple (2 or more) & $14(11)$ & $3(19)$ & $11(10)$ & \\
\hline Referring physician type (\%) & & & & 0.79 \\
\hline Pediatrician & $111(87)$ & $15(94)$ & $96(86)$ & \\
\hline Family practitioner & $9(7)$ & $0(0.0)$ & $9(8)$ & \\
\hline Specialist & $7(6)$ & $1(6)$ & $6(5)$ & \\
\hline
\end{tabular}

GED = general educational development.

* Calculated using median household income based on zip code of residence from US Census reports.

IQR 43-87 days] vs median 56 days [African American; IQR 36-98 days], respectively; $\mathrm{p}=0.20$ ).

\section{Distance for Evaluation and Treatment}

Distance traveled to receive initial evaluation and surgical treatment was also evaluated (Table 3). The median distance from the patient's home zip code to the referring provider and to MCJCHV for the overall cohort was 13.2 miles (IQR 0-22.6 miles) and 50.3 miles (IQR 20.6-102.7 miles), respectively. When stratified by race, there was no significant difference in overall distance traveled between African American and Caucasian patients. Although not statistically significant, African American patients tended to live closer to their referring providers as compared with Caucasian patients (median 10.5 miles [IQR 0-21.2 miles] vs median 13.2 miles [IQR 0-23.3 miles], respectively). The same pattern was observed when comparing distance in miles to MCJCHV between African American and Caucasian patients (median 20.6 miles [IQR 14.766.9 miles] vs median 52.0 miles [IQR 24.7-108.0 miles], respectively).

\section{Discussion}

Disparity in health care access has been identified in a variety of medical conditions. In adult medicine differences in access, treatment, and overall outcomes have been described among disease states such as heart disease, ${ }^{8,12,18,24}$ cancer, ${ }^{1,8,15,17,23}$ and diabetes. ${ }^{25,27} \mathrm{Li}$ et al. ${ }^{18}$ retrospectively reviewed data for 207,570 Medicare enrollees hospitalized for acute myocardial infarction in Pennsylvania be- 
TABLE 2. Median age at initial consultation and time to surgery by race

\begin{tabular}{lcccc}
\hline \multicolumn{1}{c}{ Variable } & $\begin{array}{c}\text { Overall } \\
\text { Cohort }\end{array}$ & $\begin{array}{c}\text { African } \\
\text { American }\end{array}$ & Caucasian & p Value \\
\hline Age at consult (days) & 148 & 341 & 137 & 0.0012 \\
\hline Time to op (days) $\dagger$ & 64 & 56 & 64 & 0.20 \\
\hline
\end{tabular}

* Number of days between patient's date of birth and date of initial consultation with either neurosurgical or plastic surgeons.

$\dagger$ Number of days between date of patient's initial surgical consultation and date of surgery.

tween 1995 and 2006. They found that African American patients tended to be sicker at the time of admission yet were significantly less likely to receive a coronary artery bypass graft or percutaneous coronary intervention within 3 months ( $\mathrm{p}<0.0001$ for both procedures). Albain et al. ${ }^{1}$ reviewed 19,457 adult cancer patients treated in 35 Southwest Oncology Group randomized Phase III clinical trials from October 1974 to November 2009. Patients received uniform treatment and follow-up care. Despite adjusting for stage, socioeconomic factors, and known prognostic characteristics, African Americans experienced worse overall survival for breast, prostate, and ovarian cancers. Mayberry et al. conducted a review of nearly 400 studies from 1995 to 1999 to describe factors that contribute to disparities in access to health services..$^{20}$ These authors found that across wide-ranging diseases, African American and ethnic minorities often lacked the same access to medical treatment and health services compared with Caucasians.

All patients in our cohort had an established primary provider. Despite having access to someone who could identify the patients' need for referral and/or intervention, African American children were significantly older at the time of initial consultation. However, once the patient was seen by a specialist, time to surgery was not significantly different between groups. This finding is consistent with results from a previous study analyzing data from 2608 children (ages 4-35 months) from the 2000 National Survey of Early Childhood Health, which found that the odds of being referred to a specialist significantly differed by race. In craniosynostosis, it has been suggested that delays in being referred for care can negatively impact clinical outcomes, as children are more likely to benefit from surgical intervention within the first year of life., ${ }^{910,16,21,22,26,30}$ Additionally, recent studies evaluating outcomes in children with craniosynostosis report differences in age at the time of surgery between racial groups. Lin et al. examined the impact of demographic factors on age and found that African American or Hispanic race/ethnicity was significantly associated with older age at surgery $(p=0.022) .{ }^{19}$ Faris et al. evaluated the impact of race on surgical outcomes of 3415 children surgically treated for craniosynostosis between 2000 and 2009 identified using the national Kids' Inpatient Database. ${ }^{28}$ Similarly, they report that Caucasian patients were significantly younger at the time of surgery as compared with African American or Hispanic patients $(6.1,10.9$, and 9.1 months, respectively; $\mathrm{p}<0.0001)$.
TABLE 3. Median distance to PCP and to MCJCHV by race

\begin{tabular}{|c|c|c|c|c|}
\hline Variable & $\begin{array}{l}\text { Overall } \\
\text { Cohort }\end{array}$ & $\begin{array}{c}\text { African } \\
\text { American }\end{array}$ & Caucasian & $\mathrm{p}$ Value \\
\hline Distance to PCP (miles) & 13.2 & 10.5 & 13.2 & 0.89 \\
\hline $\begin{array}{l}\text { Distance to MCJCHV } \\
\text { (miles) } \dagger\end{array}$ & 50.3 & 20.6 & 52.0 & 0.24 \\
\hline
\end{tabular}

Further literature on disparities specific to the craniosynostosis pediatric population is limited; however, barriers related to other craniofacial disorders have been described. ${ }^{6,13}$ Cassell et al. evaluated maternal perceived barriers to care among children with orofacial clefts in North Carolina. ${ }^{7}$ When asked open-endedly about problems receiving care for "your child with facial differences," major themes were financial, structural, and personal barriers. Key words such as services (lack, inadequate), access, provider knowledge, and referral system were used when describing structural barriers. Respondents considered availability of transportation and availability of child care to be personal barriers. Cost, co-pays, and insurance were key words reported for financial barriers. These barriers, although not specific to the craniosynostosis population, may be relevant to our patients.

Another explanation for the difference between racial groups may be an indirect result of distrust in the medical system within the African American community, resulting in delays to seeking medical care. In 2003, Boulware et al. conducted a cross-sectional study to compare differences in trust in physicians, hospitals, and health insurance plans among non-Hispanic African Americans and Caucasians. ${ }^{3}$ This study found that non-Hispanic African American respondents were 1) less likely to trust their physician, 2) more likely to have concerns regarding personal privacy, and 3) more likely to voice concerns about the potential for harmful experimentation in hospitals. ${ }^{3}$ More recently, Braunstein et al. evaluated more than 700 patients' individual perception of the risks and benefits of participating in research trials and distrust toward medical researchers. ${ }^{4}$ Similarly, the study found that African Americans were less willing to participate in research and consistently reported greater overall distrust of medical researchers than Caucasians. Significantly more African Americans believed "doctors very often, fairly often, or did not know how often prescribed medications as a way of experimenting on people without their knowledge or consent" as compared with Caucasians $(58 \%$ vs $25 \%$, respectively; $\mathrm{p}<0.001)$. Among respondents who were willing to participate in the drug trial, overall distrust among African Americans was still higher compared with Caucasians. Distrust in the medical community and health care providers, similar to findings from previous studies, may have caused hesitancy in seeking care among our African American patient population. If true, this would potentially explain the longer time for specialist referral and older age at consultation we observed. 
Lastly and perhaps most importantly, our findings may be the direct result of a general lack of knowledge about craniosynostosis among patient families and health care providers. The ability of caregivers and primary care providers to recognize early signs of craniosynostosis can impact the likelihood of a child being diagnosed earlier versus later, and subsequently initiated into care. If they are better informed, they may be more likely to recognize physical signs of craniosynostosis (abnormal skull shape, prematurely closing fontanel, slow head growth) and seek treatment. If community providers are trained to identify and appropriately diagnose craniosynostosis, they may be more likely to initiate referral to specialty care earlier. All patients in our study cohort reported having a regular health care provider who would be able to diagnose their craniosynostosis. However, if those providers lack sufficient knowledge, or are not aware of when specialty care is warranted, missed opportunities for early intervention can occur. Additionally providers who are less aware/knowledgeable may not routinely screen their patient population, resulting in later diagnosis and subsequent care. It is imperative that the surgical subspecialists and craniofacial team are active in the education process. Whether by engaging in community provider or pediatric resident lectures, education regarding diagnoses and treatment of craniosynostosis can be improved. In many cases, providers simply do not know that timing could potentially affect outcome or that different therapies can be used at an earlier age.

Our study was subject to inherent limitations of its design. Due to the retrospective nature of the study, we are left with only answering that a disparity exists and that it appears to disappear once children are evaluated by specialty care providers. It will have to be left to further studies, ideally multiinstitutional, to further investigate the exact reasons. Future studies should 1) assess the level of general knowledge about craniosynostosis among providers and patient families, 2) identify reasons for delays prior to specialty referral on the part of the family and primary care provider, and 3) provide general craniosynostosis education at both the community and provider levels. An additional limitation of our study is due to our small sample size. As a result, this may have limited our ability to detect statistical differences between groups. Therefore, our findings may not be representative of pediatric craniosynostosis populations at other institutions, thereby limiting generalizability. In addition, there may be many more African American children who were never diagnosed, and therefore not represented in this study population.

\section{Conclusions}

In this study we investigated perceived disparities in access among the pediatric craniosynostosis population at the MCJCHV. We identified a correlation between race and age at consultation but no association with time to surgery, distance, or family characteristics such as household income, parental education, insurance type, and referring physician type. Future efforts should focus on further identifying and examining barriers, and creating educational efforts within the affected community, including the health care providers who serve them.

\section{Acknowledgments}

We would like to thank Dr. Chevis N. Shannon (editing), Reagan Major (data collection), and Rachel Pellegrino (data collection) for invaluable contributions to this study. This research was supported in part by the Surgical Outcomes Center for Kids at MCJCHV and through the Section for Surgical Sciences at Vanderbilt University Medical Center.

\section{References}

1. Albain KS, Unger JM, Crowley JJ, Coltman CA Jr, Hershman DL: Racial disparities in cancer survival among randomized clinical trials patients of the Southwest Oncology Group. J Natl Cancer Inst 101:984-992, 2009

2. Berkowitz SA, Traore CY, Singer DE, Atlas SJ: Evaluating area-based socioeconomic status indicators for monitoring disparities within health care systems: results from a primary care network. Health Serv Res 50:398-417, 2015

3. Boulware LE, Cooper LA, Ratner LE, LaVeist TA, Powe NR: Race and trust in the health care system. Public Health Rep 118:358-365, 2003

4. Braunstein JB, Sherber NS, Schulman SP, Ding EL, Powe NR: Race, medical researcher distrust, perceived harm, and willingness to participate in cardiovascular prevention trials. Medicine (Baltimore) 87:1-9, 2008

5. Buchanan EP, Xue AS, Hollier LH Jr: Craniofacial syndromes. Plast Reconstr Surg 134:128e-153e, 2014

6. Cassell CH, Daniels J, Meyer RE: Timeliness of primary cleft lip/palate surgery. Cleft Palate Craniofac J 46:588597,2009

7. Cassell CH, Mendez DD, Strauss RP: Maternal perspectives: qualitative responses about perceived barriers to care among children with orofacial clefts in North Carolina. Cleft Palate Craniofac J 49:262-269, 2012

8. Chang MH, Moonesinghe R, Athar HM, Truman BI: Trends in disparity by sex and race/ethnicity for the leading causes of death in the United States-1999-2010. J Public Health Manag Pract 22 Suppl 1:S13-S24, 2015

9. Cohen SR, Cho DC, Nichols SL, Simms C, Cross KP, Burstein FD: American Society of Maxillofacial Surgeons outcome study: preoperative and postoperative neurodevelopmental findings in single-suture craniosynostosis. Plast Reconstr Surg 114:841-849, 2004

10. Da Costa AC, Anderson VA, Holmes AD, Lo P, Wray AC, Chong DK, et al: Longitudinal study of the neurodevelopmental characteristics of treated and untreated nonsyndromic craniosynostosis in infancy. Childs Nerv Syst 29:985-995, 2013

11. Fiscella K, Franks P, Doescher MP, Saver BG: Disparities in health care by race, ethnicity, and language among the insured: findings from a national sample. Med Care 40:52-59, 2002

12. Graham G: Population-based approaches to understanding disparities in cardiovascular disease risk in the United States. Int J Gen Med 7:393-400, 2014

13. Hanny KH, de Vries IA, Haverkamp SJ, Oomen KP, Penris WM, Eijkemans MJ, et al: Late detection of cleft palate. Eur J Pediatr 175:71-80, 2016

14. Jimenez DF, Barone CM: Endoscopic craniectomy for early surgical correction of sagittal craniosynostosis. J Neurosurg 88:77-81, 1998

15. Kanna B, Narang TK, Atwal T, Paul D, Azeez S: Ethnic disparity in mortality after diagnosis of colorectal cancer among inner city minority New Yorkers. Cancer 115:5550-5555, 2009

16. Kapp-Simon KA, Leroux B, Cunningham M, Speltz ML: Multisite study of infants with single-suture craniosynostosis: preliminary report of presurgery development. Cleft Palate Craniofac J 42:377-384, 2005 
17. Laiyemo AO, Doubeni C, Pinsky PF, Doria-Rose VP, Bresalier R, Lamerato LE, et al: Race and colorectal cancer disparities: health-care utilization vs different cancer susceptibilities. J Natl Cancer Inst 102:538-546, 2010

18. Li S, Chen A, Mead K: Racial disparities in the use of cardiac revascularization: does local hospital capacity matter? PLoS One 8:e69855, 2013

19. Lin Y, Pan IW, Harris DA, Luerssen TG, Lam S: The impact of insurance, race, and ethnicity on age at surgical intervention among children with nonsyndromic craniosynostosis. J Pediatr 166:1289-1296, 2015

20. Mayberry RM, Mili F, Ofili E: Racial and ethnic differences in access to medical care. Med Care Res Rev 57 (Suppl 1):108-145, 2000

21. Panchal J, Amirsheybani H, Gurwitch R, Cook V, Francel P, Neas B, et al: Neurodevelopment in children with single-suture craniosynostosis and plagiocephaly without synostosis. Plast Reconstr Surg 108:1492-1500, 2001

22. Patel A, Yang JF, Hashim PW, Travieso R, Terner J, Mayes LC, et al: The impact of age at surgery on long-term neuropsychological outcomes in sagittal craniosynostosis. Plast Reconstr Surg 134:608e-617e, 2014

23. Pisu M, Kenzik KM, Oster RA, Drentea P, Ashing KT, Fouad $\mathrm{M}$, et al: Economic hardship of minority and non-minority cancer survivors 1 year after diagnosis: another long-term effect of cancer? Cancer 121:1257-1264, 2015

24. Rangrass G, Ghaferi AA, Dimick JB: Explaining racial disparities in outcomes after cardiac surgery: the role of hospital quality. JAMA Surg 149:223-227, 2014

25. Rosenstock S, Whitman S, West JF, Balkin M: Racial disparities in diabetes mortality in the 50 most populous US cities. J Urban Health 91:873-885, 2014

26. Ruiz-Correa S, Starr JR, Lin HJ, Kapp-Simon KA, Cunningham ML, Speltz ML: Severity of skull malformation is unrelated to presurgery neurobehavioral status of infants with sagittal synostosis. Cleft Palate Craniofac J 44:548-554, 2007

27. Shi Q, Zhao Y, Fonseca V, Krousel-Wood M, Shi L: Racial disparity of eye examinations among the U.S. workingage population with diabetes: 2002-2009. Diabetes Care 37:1321-1328, 2014

28. Shweikeh F, Foulad D, Nuño M, Drazin D, Adamo MA: Differences in surgical outcomes for patients with craniosynostosis in the US: impact of socioeconomic variables and race. J Neurosurg Pediatr 17:27-33, 2016
29. Smedley BD, Stith AY, Nelson AR (eds): Unequal Treatment: Confronting Racial and Ethnic Disparities in Health Care. Washington, DC: The National Academies Press, 2003

30. Speltz ML, Collett BR, Wallace ER, Starr JR, Cradock MM, Buono L, et al: Intellectual and academic functioning of school-age children with single-suture craniosynostosis. Pediatrics 135:e615-e623, 2015

31. Wong-Gibbons DL, Kancherla V, Romitti PA, Tyler MC, Damiano PC, Druschel CM, et al: Maternal reports of satisfaction with care and outcomes for children with craniosynostosis. J Craniofac Surg 20:138-142, 2009

\section{Disclosures}

The authors report no conflict of interest concerning the materials or methods used in this study or the findings specified in this paper.

\section{Author Contributions}

Conception and design: Brown, Kevin Kelly, Wellons. Acquisition of data: Brown, Westrick, Katherine Kelly. Analysis and interpretation of data: Westrick. Drafting the article: Bey, Brown, Westrick, Katherine Kelly. Critically revising the article: Bey, Bonfield, Wellons. Reviewed submitted version of manuscript: Bey, Brown, Bonfield, Kevin Kelly, Wellons. Approved the final version of the manuscript on behalf of all authors: Bey. Statistical analysis: Bey. Study supervision: Wellons.

\section{Supplemental Information \\ Previous Presentations}

Portions of this work were presented in poster form at the Tennessee Louis Stokes Alliance for Minority Participation Conference, Nashville, Tennessee, February 26, 2015, and the Black Doctoral Network Conference, Philadelphia, Pennsylvania, October 25, 2014.

\section{Correspondence}

Amita Bey, Monroe Carell Jr. Children's Hospital, 2200 Children's Way, 9222 Doctors' Office Tower, Nashville, TN 372329557.email: amita.k.bey@vanderbilt.edu. 